\title{
Promoting Participation of Stakeholders in Community-Based Rehabilitation in Sri Lanka: Process of Action Research in Anuradhapura
}

\author{
Masateru Higashida ${ }^{1}$, M.R. Shantha Kumara ${ }^{2}$, Menikralage Gamini Illangasingha ${ }^{3}$ \\ ${ }^{1}$ Japan International Cooperation Agency (JICA), Colombo, Sri Lanka \\ ${ }^{2}$ Department of Social Services, Sethsiripaya, Battaramulla, Sri Lanka \\ ${ }^{3}$ Department of Social Services, Anuradhapura Kachcheriya, Sri Lanka \\ Correspondence: Masateru Higashida, Japan International Cooperation Agency (JICA), Colombo, Sri Lanka. \\ mhigashid@gmail.com
}

Received: February 21, 2015

Accepted: March 17, 2015

Available online: March 19, 2015

doi:10.11114/ijsss.v3i3.732

URL: http://dx.doi.org/10.11114/ijsss.v3i3.732

\begin{abstract}
This study examines the participation of stakeholders, including disabled people, in disability and community issues in rural areas in Sri Lanka. As a conceptual framework, four dimensions of participation in community-based rehabilitation (CBR) are summarised from previous research. This research was mainly conducted in the model administrative division of the national CBR programme in Anuradhapura district. An action research approach was applied in March 2013, which consisted of eight steps. The study used data from the hearing survey on disabled children under 18 years old $(n=103)$, semi-structured interviews with disabled people $(n=20)$, focus group discussions with participants of community workshops $(n=34)$ and social services officers $(n=5)$ separately, and the authors' field notes, amongst others. Data were analysed with a qualitative procedure, except for quantitative data. Showing the four dimensions of participation in each step, we found promoting participation of various stakeholders improved disabled people's living conditions and enhanced their empowerment. The study also revealed elements that were significant in promoting participation through the action research process: key persons, information and network, utilising existing local resources, dialogue in meetings, and multisectional practice. Finally, we discuss the theoretical implications of this research.
\end{abstract}

Keywords: community-based rehabilitation, community participation, inclusive development

\section{Introduction}

Community-Based Rehabilitation (CBR) is defined as 'a strategy within general community development for the rehabilitation, equalization of opportunities and social inclusion of all people with disabilities' (ILO, UNESCO \& WHO, 2004).

Participation in communities is one of the most significant concepts in disability issues and CBR. For instance, the United Nations Convention on the Rights of Persons with Disabilities (UNCRPD) underlines the significance of disabled people's full and effective participation in society on an equal basis with others (United Nations, 2006). The United Nations (2000) also emphasise the human rights of disabled people to participate fully in social life and community development, enjoy living conditions equal to those of other citizens, and share equal conditions improved by socio-economic development. The CBR guidelines state 'it is important that all key stakeholders, particularly people with disabilities and their family members, are actively involved at all stages of the management cycle'(WHO, 2010: 36).

The definition of community participation ranges from passive beneficiaries to activators making decisions (Rifkin \& Kangare, 2002). Rifkin et al. state that '[c]ommunity participation is a social process whereby specific groups with shared needs living in a defined geographic area actively pursue identification of their needs, take decisions and establish mechanisms to meet these needs' (Rifkin, Muller \& Bichmann, 1988: 933). Boyce and Lysack (2000) define community participation in the context of CBR as the organisation of activities by disabled people's groups, in conjunction with other stakeholders, to increase their ability to change society.

According to a literature review of CBR, however, only a few papers are available on participation (Finkenflügel, 
Wolffers \& Huijsman, 2005). One of the research papers critically discusses community participation from the perspective of inadequate CBR guidelines, which are not always applicable to the field level (Pollard \& Sakellariou, 2008). In addition, a structural concept of participation in CBR has not been available.

Therefore, four dimensions of participation in CBR are summarised from previous literatures in Table 1. The stakeholders are divided into disabled people (primary stakeholders) and all key stakeholders (secondary stakeholders). The types of participation areas are also classified into disability issues and community issues, whilst using the framework of the twin-track approach, which emphasises the importance of a simultaneous process of empowerment and inclusion (International Disability and Development Consortium, 2012; Kuno \& Seddon, 2003). The four dimensions of criteria overlap with each other.

In Sri Lanka, the CBR was launched as a pilot project in 1981 and has been developed as the national programme since 1994. The Ministry of Social Services (2012) in Sri Lanka created the draft of the five-year plan on the national CBR programme in line with the WHO's CBR guidelines. The programme has been implemented within 331 divisional secretariats in 25 districts, which cover all of the administrative divisions in Sri Lanka as of 2012 (Ministry of Social Services, 2013). As of August 2014, a total of 472 officers are in charge of the national CBR programme, including a social services officer (SSO), social development assistant, and development officer. Nonetheless, the Ministry (2012) mentions the constraints on the programme: poor planning, not following the sequence of stages when expanding the programme, inadequate or lack of multisectional collaboration, and inadequacies in capacity building. The practice and effectiveness of CBR in Sri Lanka has rarely been studied and presented.

The aim of this study is to examine the participation of stakeholders, including disabled people, in disability issues and community issues, with the overall objective of promoting participation in rural areas in Sri Lanka. In particular, this study focuses on the elements and process of promoting the participation of all key stakeholders.

Table 1. Dimensions of participation in CBR

\begin{tabular}{lll}
\hline \multicolumn{1}{c}{ Participants } & \multicolumn{1}{c}{ Disability issues } & \multicolumn{1}{c}{ Community issues } \\
\hline (Primary) & empowerment, & self-advocacy, \\
disabled people & conscientization ${ }^{\text {a }}$, etc.
\end{tabular}

\begin{tabular}{|c|c|c|}
\hline $\begin{array}{l}\text { (Secondary) } \\
\text { community } \\
\text { stakeholders }\end{array}$ & $\begin{array}{l}\text { awareness raising, multisectional } \\
\text { approach, community mobilisation, } \\
\text { etc. }\end{array}$ & community development, etc. \\
\hline & (D-II) & (D-IV) \\
\hline
\end{tabular}

Description: Cites the idea of 'twin-track approach' (International Disability and Development Consortium, 2012; Kuno \& Seddon, 2003).

${ }^{\text {a }}$ Adapted from Freire (1970).

${ }^{\mathrm{b}}$ Shows one of the dimensions of the purposes of participation in CBR.

\section{Methods}

After commencing work in a local government office as an overseas volunteer in February of 2013, the first author applied action research.

Action research was innovated as 'comparative research on the conditions and effects of various forms of social action, and research leading to social action' (Lewin, 1946: 35). Action research has developed into participatory action research (PRA) and participatory learning and action (PLA), which place more importance on empowerment and advocacy in the process, because they essentially transform power relations in the direction of greater democracy (Greenwood \& Levin, 1998). Some researchers utilised PRA in the context of CBR (Gauld, Smith \& Kendall, 2011).

A triangulation approach, adopting more qualitative and less quantitative research, was used for the action research (Higashida, 2014a; Higashida, 2014b; Higashida, Illangasingha \& Kumara, 2015). This is partly because qualitative data allow for clear and in-depth insights into values and contexts in CBR, which enable more holistic data to be extracted (Sharma, 2004).

\subsection{Study Site}

The target study site is Anuradhapura district, which consists of 22 government administrative divisions including R-division, I-division, Ta-division, M-division and Ti-division (fictitious names). The population of Anuradhapura district is enumerated at 855,562 (Department of Census and Statistics, 2012). The total number of disabled people registered by Anuradhapura district is 8,364, as of 2013 . 
The research is mainly implemented in R-division, which is the model administrative division of the national CBR programme. R-division is located in the southern part of Anuradhapura district. The population of R-division is estimated at 32,684 as of December 2013. The Sinhalese people, who are mostly Theravada Buddhists, constitute more than $99 \%$ of the population. There are two hospitals, a Medical Officer of Health (MOH), and two special needs classes. In this division, the CBR programme began in 1998, and Japan International Cooperation Agency (JICA) volunteers commenced support activities in 2007. The number of disabled people in R-division is shown in Table 2. The proportion of disabled people registered at the divisional secretariat office in R-division is approximately $1.1 \%$ of the total residents in 2013.

Table 2. Registered disabled people in R-division

\begin{tabular}{lcccc}
\hline \multicolumn{1}{c}{ Types } & Male & Female & Total & \% of total \\
\hline Physical dis ability & 51 & 36 & 87 & $24 \%$ \\
Intellectual disability & 42 & 42 & 84 & $23 \%$ \\
Visual dis ability & 25 & 23 & 48 & $13 \%$ \\
Hearing disability & 19 & 20 & 39 & $11 \%$ \\
Speech and hearing disability & 15 & 10 & 25 & $7 \%$ \\
Severe multi-disabilities & 13 & 17 & 30 & $8 \%$ \\
Others & 25 & 25 & 50 & $14 \%$ \\
\hline Total & 190 & 173 & 363 & $100 \%$ \\
\hline
\end{tabular}

Description: Data were collected from the official record at the local government office in 2013.

\subsection{Study process and duration}

The spiral process in action research involves a 'non-linear pattern of planning, acting, observing, and reflecting on the changes in the social situations' (Noffke \& Stevenson, 1995: 2). In this study, it was important to flexibly rethink the next step and strategy in line with the needs and changes in circumstances.

As shown in Figure 1, this research has eight steps: (1) identifying the community situation; (2) observing life conditions and local resources; (3) planning to promote participation and strengthen the network; (4) acting based on the plan; (5) observing progress; (6) identifying the situation of participation and building networks in educational issues; (7) planning to promote participation in education; and (8) observing launched local resources and community participation. Reflection is also a fundamental process that connects each step. The research period is from $1^{\text {st }}$ March 2013 to $30^{\text {th }}$ November 2014 .

It is obvious that the process is neither simple nor linear. This is partly because we commenced activities in the ongoing programme. For instance, it was necessary to observe the existing activities at an early stage (step 2). Additionally, one activity had impacts on the other activities in the process. For example, identifying the situation of participation and building networks in educational issues (step 6) was decided through reflection after observation (step 2).

\begin{tabular}{|c|c|c|c|c|c|}
\hline \multirow{2}{*}{ Identify } & Mar-Jun 2013 & Jul-Oct 2013 & Nov 2013-Feb 2014 & Mar-Jun 2014 & Jul-Sep 2014 \\
\hline & \multirow{2}{*}{ Step 1} & \multirow[b]{2}{*}{ Step 3} & Step 6 & & \\
\hline Plan & & & & $\begin{array}{c}\vee \\
\text { Step } 7\end{array}$ & \\
\hline Act & & & & $\hat{\imath}$ & $\hat{\imath}$ \\
\hline \multirow[t]{2}{*}{ Observe } & \multirow{2}{*}{\multicolumn{2}{|c|}{ Step 2}} & & & \\
\hline & & & Step 5 & & tep 8 \\
\hline
\end{tabular}

Operation period

Reflect

Pending or interruption

Figure 1. Eight Steps of the Research Process 


\subsection{Data collection}

Statistical data were collected from the documented sources (e.g. local government documents) and fieldwork, including home visits and meetings.

Semi-structured interviews with disabled people were conducted. Their family members also participated in the interviews to support them in answering, in case the disabled people had difficulties in understanding and answering. Table 3 presents the list of 20 interviewees. All interviews were conducted by two interviewers in Sinhalese, which is the native language of the study site. Interviews were guided by semi-structured questions to stimulate dialogue. Participants were briefed about ground rules to ensure confidentiality and the objectives of the study. It was emphasised that the interview was not meant for personal assessment.

Focus group discussions were carried out with participants of community workshops ( $\mathrm{n}=34)$ and CBR core group officers ( $n=5)$ separately. Questions with probes for discussions were developed based on the aim of the study.

Data from other methods, such as mapping, stakeholder analysis (Kumar, 2002; WHO, 2010), and field notes in social work practice were also used to analyse the realities in the study. In particular, the narrative data were utilised in the process of interpretation and analysis.

Table 3. List of Interviewees

\begin{tabular}{|c|c|c|c|c|c|}
\hline No. & Age & Sex & Type of dis abilities & $\begin{array}{c}\text { Main } \\
\text { activities }^{\mathrm{a}}\end{array}$ & Step $^{b}$ \\
\hline 1 & 17 & $\bar{F}$ & Intellectual disability & $\mathrm{C}$ & Step2 \& 6 \\
\hline 2 & 19 & $\mathrm{~F}$ & Intellectual disability & $\mathrm{C}$ & Step2 \\
\hline 3 & 19 & $\mathrm{~F}$ & $\begin{array}{l}\text { Traumatic higher } \\
\text { brain dysfunction }\end{array}$ & $\mathrm{C}, \mathrm{V}$ & Step2 \\
\hline 4 & 22 & $\mathrm{M}$ & $\begin{array}{l}\text { Cerebral palsy, } \\
\text { asphyxia, epilepsy }\end{array}$ & $\mathrm{C}$ & Step2 \\
\hline 5 & 23 & $\mathrm{M}$ & Epilepsy & $\mathrm{C}, \mathrm{V}$ & Step2 \\
\hline 6 & 26 & $\mathrm{~F}$ & Intellectual disability & $\mathrm{C}$ & Step $2 \& 6$ \\
\hline 7 & 26 & $\mathrm{M}$ & Auditory disability & $\mathrm{C}$ & Step2 \& 6 \\
\hline 8 & 27 & $\mathrm{~F}$ & Intellectual dis ability & $\mathrm{C}$ & Step $2 \& 6$ \\
\hline 9 & 30 & $\mathrm{M}$ & $\begin{array}{l}\text { Epilepsy, intellectual } \\
\text { disability }\end{array}$ & $\mathrm{C}$ & Step2 \\
\hline 10 & 35 & $\mathrm{M}$ & $\begin{array}{l}\text { Epilepsy, intellectual } \\
\text { disability }\end{array}$ & $\mathrm{C}$ & Step2 \\
\hline 11 & 52 & $\mathrm{~F}$ & Polio & $\mathrm{C}$ & Step2 \\
\hline 12 & 37 & $\mathrm{~F}$ & Down's syndrome & $\mathrm{C}$ & Step6 \\
\hline 13 & 13 & $\mathrm{M}$ & Intellectual disability & - & Step6 \\
\hline 14 & 22 & $\mathrm{~F}$ & Down's syndrome & - & Step6 \\
\hline 15 & 28 & $\mathrm{M}$ & Down's syndrome & - & Step6 \\
\hline 16 & 20 & $\mathrm{M}$ & $\begin{array}{l}\text { Down's syndrome, } \\
\text { Epilepsy }\end{array}$ & - & Step6 \\
\hline 17 & 16 & $\mathrm{M}$ & Down's syndrome & - & Step6 \\
\hline 18 & 12 & $\mathrm{M}$ & Autism & - & Step6 \\
\hline 19 & 24 & $\mathrm{~F}$ & Intellectual dis ability & - & Step6 \\
\hline 20 & 24 & M & Intellectual dis ability & - & Step6 \\
\hline
\end{tabular}

Description:

${ }^{\mathrm{a}} \mathrm{C}=$ Community workshop and steering committee, $\mathrm{V}=\mathrm{CBR}$ volunteer

${ }^{\mathrm{b}}$ Data in step 2 were used in previous study (Higashida, 2014a)

\subsection{Data analysis}

The interview data were analysed with reference to the KJ method (Kawakita, 1967). This approach emphasises the significance of context in analysing and understanding data. Four raters, including two interviewers, conducted the analysis, which consisted of eight steps: carefully transcribing and reading interviews; putting transcribed data onto sticky notes; putting sticky notes on a white board; positioning and grouping similar sticky notes; naming each group; drawing lines between groups in accordance with relevance; considering appropriate labels; and verifying the traceability of each interviewee. 
Data from the other methods were descriptively summarised with assistance from study participants. Statistical data were analysed by descriptive statistics.

We describe the results chronologically in line with the steps of the research process (Figure 1), whilst utilising the framework of dimensions of participation (Table 1).

\subsection{Study Participants}

Whereas this paper focuses on participation, the initial method was not PRA. One of the reasons is that the first author took part in the existing activities, and had to learn the situation and context related to the CBR programme from local people at the time, which can be described as participant observation. We gradually shifted to PRA during the process of the study.

Local stakeholders participated in the study. An SSO at the local government office, who manages the CBR programme in the study area, is the first author's official counterpart, advisor and co-conductor. A CBR coordinator at the Department of Social Services (the second author), a chief social services officer in the district (the third author), a divisional secretary, zonal educational officers, medical officers of health, and CBR volunteers including disabled people were supportive participants in the research. Disabled people, their family members, and other CBR core group officers in the district took part in research activities such as participatory evaluation.

\subsection{Ethical Consideration}

The study was approved by the Department of Social Services, the local government office, and the JICA office in Sri Lanka. Disabled interviewees were verbally asked to participate after receiving information in their native Sinhalese language. They were assured that refusal to be interviewed would have no impact on the services provided. Family carers who helped a disabled person on a regular basis were asked to participate and to consent to the participation of the disabled person. Consent was also sought on an ongoing basis.

\section{Results}

\subsection{Step 1: Identifying the Community Situation (D-I and D-III)}

The first step of the study was conducted in two dimensions: D-I and D-III (see Table 1).

It was indispensable to clarify the community situation in the rural area. The SSO in R-division and the first author made a list of local resources used by disabled people in R-division, and a map of the main local resources, through dialogue and fieldwork.

Table 4 shows the existing local resources and the participants in the area. It is obvious that disabled people take part in not only the local resources run by them (D-I), but also those run by community stakeholders (D-III), albeit mainly with government support.

Figure 2, however, describes the gap in the density of available local resources. The local resources located in the centre of village around the divisional secretariat office and near bus streets are accessible for disabled people and their family members living in the areas. On the other hand, few resources are seen in the remaining remote area, which can lead to a gap in accessibility to participating in or use them.

\subsection{Step 2: Observing life conditions and local resources (D-I and D-III)}

After identifying the community situation, evaluation of the CBR programme in R-division was required. The main reason for this was that neither synthesis data nor reports related to outcomes and progress were available at the time, despite the fact that the local government commenced the CBR programme in 1998 and overseas volunteers started their support in 2007.

The research on the development process of local resources for disabled people was carried out, and involved interviewing 11 disabled people (Higashida, 2014a).

The analysis reveals that the living conditions of disabled people participating in local activities were improved through the development of local resources, whilst enhancing their empowerment in the process (D-I). In addition, some interviewees participated in meetings and events (e.g. youth club and village meetings) in the division after taking part in the CBR community workshops (D-III).

The analysis also indicates the challenges experienced by those who cannot take part in local activities. In particular, it suggests the issue of disabled children who do not connect with educational resources at school age, and those who have no access to local resources in spite of the fact that they have experience of special needs classes (D-I and D-III). 
Table 4. List of Local Resources in R-division

\begin{tabular}{|c|c|c|c|}
\hline Local Resources ${ }^{a}$ & Element of CBR Matrix & Initiative & $\begin{array}{c}\text { Frequency of the Use by } \\
\text { Disabled People }\end{array}$ \\
\hline \multicolumn{4}{|c|}{ Local resources conducted or run by primary stakeholders } \\
\hline $\begin{array}{l}\text { CBR divisional steering } \\
\text { committee }\end{array}$ & Empowerment & $\mathrm{DP}^{\mathrm{d}} /$ Families/Government & +++ \\
\hline $\begin{array}{l}\text { CBR village steering } \\
\text { committee }\end{array}$ & Empowerment & DP/Families/Government & +++ \\
\hline $\begin{array}{l}\text { Community workshop } \\
\text { (Pantiya) }\end{array}$ & $\begin{array}{l}\text { Livelihood/ } \\
\text { Empowerment }\end{array}$ & DP/Families/ Government & ++ \\
\hline Market & Livelihood & DP/Families & + \\
\hline CBR volunteer & Social/ Empowerment & DP/Families/ Government & +++ \\
\hline \multicolumn{4}{|c|}{ Local resources run by secondary stakeholders } \\
\hline Medical institution & Health & Public/Private & ++ \\
\hline $\begin{array}{l}\text { Medical Officer of } \\
\text { Health(MOH) }\end{array}$ & Health & Public & +++ \\
\hline Montessori (Preschool) & Education & Private & + \\
\hline School & Education & Public & + \\
\hline $\begin{array}{l}\text { Samrudhi (reducing } \\
\text { poverty) }\end{array}$ & Livelihood & Public cooperation & +++ \\
\hline Job training centre & Livelihood & Public/Private & + \\
\hline Training centre & Livelihood & Public & + \\
\hline $\begin{array}{l}\text { DS sect. of technology and } \\
\text { science }\end{array}$ & Livelihood & Government & + \\
\hline DS sect. of labour & Livelihood & Government & + \\
\hline DS sect. of social services & $\begin{array}{l}\text { Livelihood/ Social/ } \\
\text { Empowerment }\end{array}$ & Government & +++ \\
\hline DS officer (other sections) & Livelihood/ Social & Government & + \\
\hline Village meetings & Social & Residents/ Government & + \\
\hline Temple & Social & Buddhist priest & ++ \\
\hline CBR district meeting & Empowerment & DP/ Government & + \\
\hline Youth club & Social/ Empowerment & Residents/ Government & + \\
\hline
\end{tabular}

\section{Description:}

${ }^{\text {a }}$ Higashida (2014b) lists human resources in the same target area.

${ }^{\mathrm{b}}$ Noted the applicable elements of CBR matrix: health, education, livelihood, social and empowerment (WHO, 2010).

${ }^{\text {c }}$ Discussed the frequency of use with SSO: '+'= less than 10 users, ' ++ ' $=10$ to 20 users, '+++' = more than 30 users.

${ }^{\mathrm{d}} \mathrm{DP}=$ Disabled people

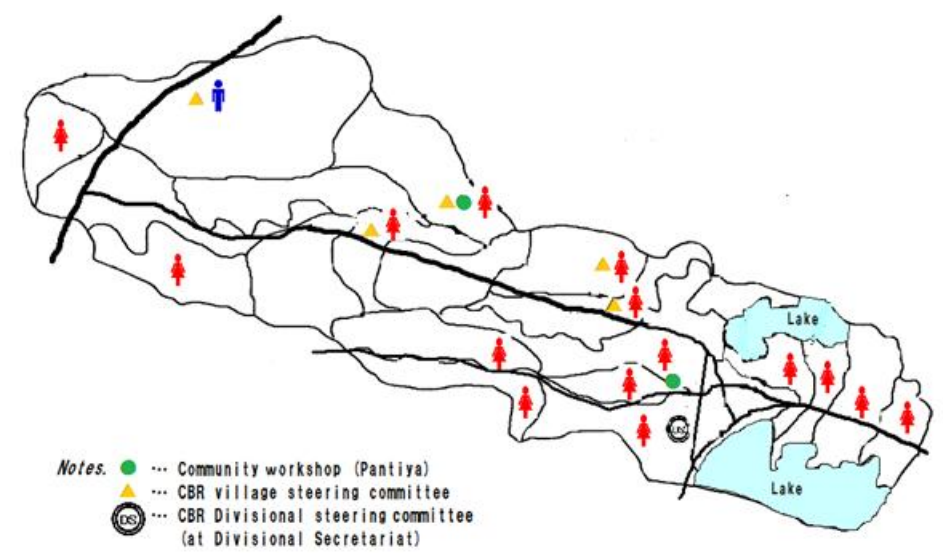

Figure 2. Mapping of main local resources in R-division (Higashida, 2014a)

\subsection{Step 3: Planning to promote participation and strengthen the network (D-I, D-II and D-III)}

Using the results of research at steps 1 and 2, the logical framework of a one-year action plan was written up by the SSO and the first author. Firstly, developing community workshops in Anuradhapura district was incorporated into the 
action plan in line with dialogue with the chief SSO (the third author) who also recommended launching community workshops in each division with reference to the model practice of R-division (D-I). Secondly, we planned to develop multisectional practice for building networks, sharing information and holding collaborative events towards inclusion (D-II and D-III).

In the process of planning with reflection, dialogue in the multi-sectional meetings in R-division was fundamental for identifying the community issues and the appropriate targets and strategies. The meetings were held with the divisional secretary, the SSO, the youth services officer, the Samrudhi officers, the zonal educational officers, and overseas volunteers (D-II).

Holding CBR steering committees was also indispensable for disabled people and their families to participate in planning activities at the grass-roots level in R-division (D-I). The CBR divisional steering committee is held once a month. CBR village steering committees of disabled people and their families are held in five villages, once every two months. Usual plans of activities are decided through the committees, whilst the SSO supports the progression.

\subsection{Step 4: Acting Based on the Plan (D-I, D-II and D-III)}

Based on the action plan, the local stakeholders and the authors implemented the actions. Although we carried out various activities at the community level, only two aspects of the implementation are presented here.

Firstly, the SSO in R-division, the chief SSO in the district (the third author), and the overseas volunteer (the first author) commenced the promotion of community workshops with disabled people and their family members in Anuradhapura district, towards the development of local resources to empower disabled people and improve their quality of life (D-I).

Setting four pilot divisions (I-division, M-division, Ta-division, Ti-division), the participants of community workshops in R-division, including disabled people, their family members and the authors, conducted the outreach courses in the five divisions including the non-target area (Figure 3). Whilst the contents of the activities were referred to R-division's practice through the outreach course, the regular activities, such as the manufacturing of daily necessities, and the operational methods were considered by participants at each community workshop: disabled people, their families and CBR core group officers (Higashida, Illangasingha \& Kumara, 2015).

Secondly, the SSO and the first author started to build a wider network with the government sections towards community-based inclusive development (CBID) in R-division. Because the number of disabled people participating in social activities was limited, the building of a network was required to promote their participation in the community.

For instance, we commenced the collection of information on disabled people with CBR volunteers and members from multisections (e.g. the medical officers of health, the health worker in a psychiatric hospital), whilst sharing the issue of the low rate of disabled people registered at the divisional secretariat office (D-II). In addition, the SSO and youth services officer collaboratively took initiatives to hold inclusive events, such as youth camps and sports events, with disabled people (D-II and D-III).

A 9-kilometre march to raise awareness of the human rights of disabled people was also carried out. More than 150 people, including disabled people, their families, local government officers of multisections, and other villagers, participated in the event with the cooperation of Ta-division's self-help group at the end of August 2013 (D-I and D-II).

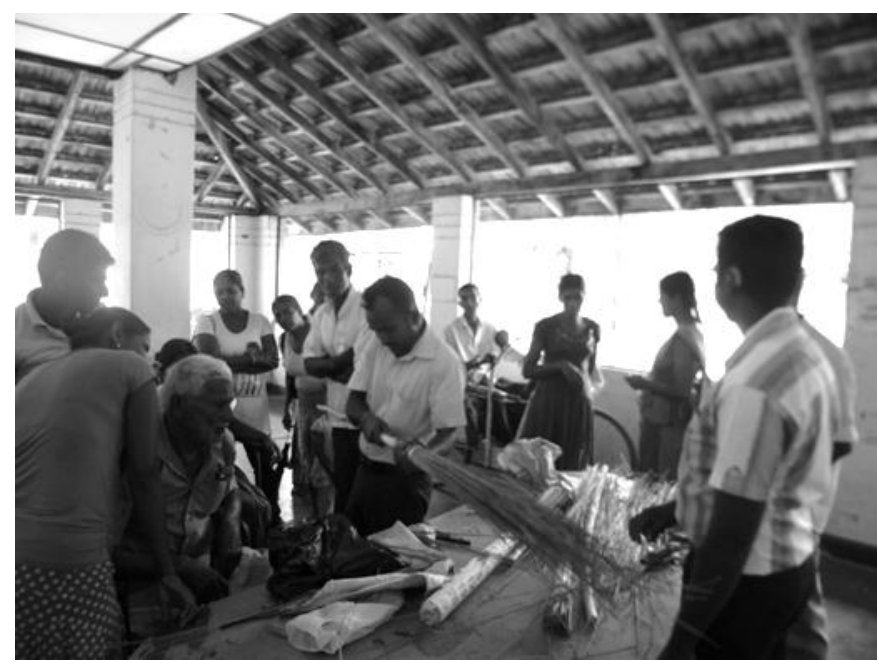

Figure 3. Outreach course in M-division 


\subsection{Step 5: Observing Progress (D-I, D-II and D-IV)}

For observing the progress of the activities based on the action plan, the divisional secretary, the SSO, the officers of the youth services and Samurudhi sections, the officers of zonal education, and overseas volunteers, held monthly or bimonthly progress meetings. Additionally, the authors shared the progress in each issue through dialogue with the study participants (D-II).

Participants also monitored the progress of activities at CBR steering committees. For example, disabled people, their families and the SSO were engaged in dialogue over the situation of the launched community workshops at each monthly committee in the four pilot divisions (D-I). The key persons, who took the initiative in running community workshops after launching, varied from place to place: mainly a CBR core group officer in I-division, family participants in Ta-division, and disabled people and a CBR core group officer in M-division, amongst others.

Furthermore, overseas volunteers, the SSO, and the chief SSO had several opportunities to present our CBR activities as the model practice at the Department of Social Services' meetings, which the second author coordinated. At the meetings, we focused on multisectional activities towards CBID, underlining the significance of community mobilisation and social change based on practice and research (D-IV).

3.6 Step 6: Identifying the situation of participation and building networks in educational issues (D-I, D-II and D-III)

In simultaneous progress with acting at step 4 and observing at step 5, the SSO and the first author decided to identify the life conditions of disabled children, because some interviewees at step 2 did not have experience of going to school or were isolated from the community after their schooling period (D-I).

The information on disabled children under 18 in R-division was collected through a hearing survey from the SSO, the $\mathrm{MOH}$, the zonal educational section, CBR volunteers, and documented data, which JICA volunteers had collected since 2008 (D-II).

A total of 103 disabled people were identified by home visits and a hearing survey with each section. Approximately $40 \%$ of them are at home with no special social activities, except for some children who supported housework. The percentage indicates the issues of the children who do not participate in social activities, including receiving education, as shown at step 2 (D-I and III).

From various educational issues, overseas volunteers conducted follow-up research on the life conditions of disabled people who had experience of going to special needs classes. A total of 13 interviewees, including four disabled people at step 2 (nos. 1, 6, 7, and 8), were identified through a method of sampling one after another, since the official information such as lists of disabled ex-pupils was not found in the education-related office nor in the schools in question. As shown in Table 3, eight interviewees (no. 13-20) did not participate in social activities at the time.

The life conditions of disabled people who have experience of special needs classes, but do not participate in CBR programmes, such as CBR village steering committees or community workshops, were analysed. Qualitative analysis reveals the gap in life conditions between those who participate in social activities and those who do not.

\subsection{Step 7: Planning to Promote Participation in Education (D-II and D-IV)}

In a joint meeting of children's development and CBR issues at the divisional secretariat office in R-division in May 2014, multisections including the social services section, the zonal education office, the child development section, and the community development section, planned new activities in the R-division, using the data on disabled children analysed at step 6 .

We focused on dropout and non-attending children under 18, including disabled children (D-II and D-IV). First, we planned to collect and integrate the information in two villages in which there were two special needs classes. Secondly, we planned to meet with the children and their family members by collaborative home visits to coordinate education opportunities for them, whilst clarifying their reason and context. Thirdly, a workshop on promoting participation in education for families and key stakeholders was planned.

\subsection{Step 8: Observing Launched Local Resources and Community Participation (D-I, D-II and D-III)}

Whilst focusing on the development of community workshops in Anuradhapura district and community participation in youth activities in R-division, we observed and reflected the CBR programme based on the action plan.

Firstly, the community workshops were evaluated in Anuradhapura district (D-I). The number of community workshops in the district increased from two places in two divisions in June 2013 to seven places in five divisions in August 2014, whereas the community workshop in Ti-division was closed. Focus group discussions with participants of the community workshops ( $n=34$, Figure 4 ) and the CBR core group officers ( $=5$, Figure 5) were implemented separately (Higashida, Illangasingha \& Kumara, 2015). 
Secondly, the overseas volunteers evaluated the participation of youth club members in the CBR programme (Higashida, 2014b). As noted in the example at step 4, the participants of community workshops in R-division always take part in youth events (e.g. youth sports festivals and youth camps). At the same time, youth club members participate in disabled people's activities on a regular basis (e.g. a dancing festival of disabled people). In addition, a disabled person (interviewee no. 10) became the officer of the youth club (D-II and D-III).

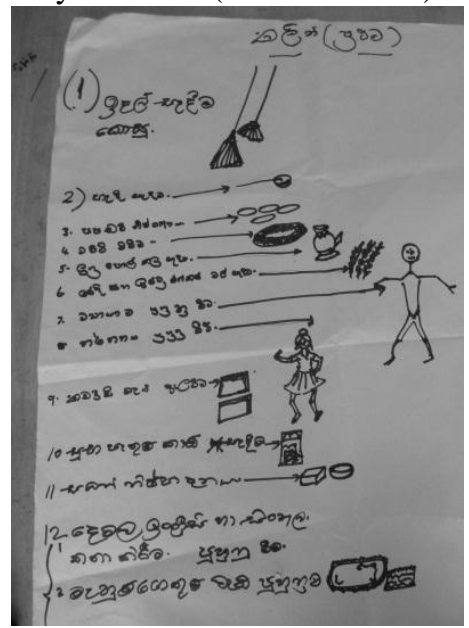

Figure 4. Picture Drawn by Participants of Community Workshop in T-division

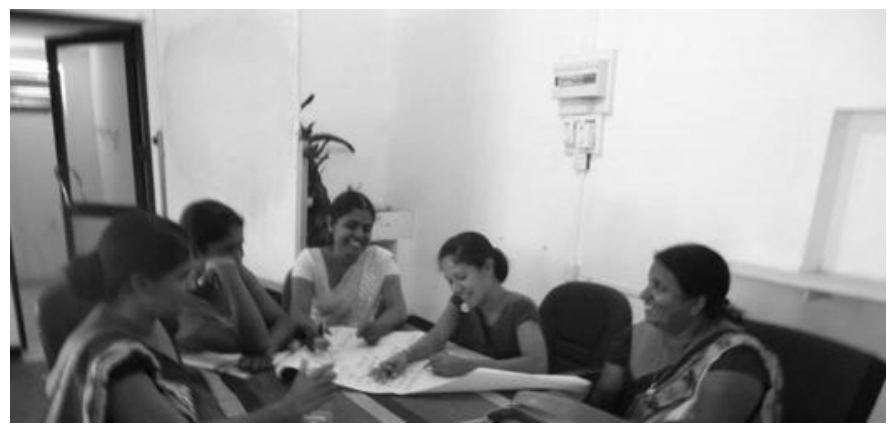

Figure 5. Participatory Evaluation with CBR Core Group Officers in Anuradhapura District

\section{Conclusion}

\subsection{Summary and Implications}

The present study attempted to examine the participation of stakeholders, including disabled people, in rural areas in the national CBR programme. It showed the process of research and actions and important elements in participation via action research.

As indicated in the process, promoting participation of the primary stakeholders (disabled people) led to empowerment and an improvement in their quality of life (D-I and D-III). The key points for promoting participation were key persons, information and networks, utilising existing local resources and dialogue in meetings. Under the limited situations of local resources and time, this paper shows the case of a feasible promotion of various stakeholders' participation in rural areas.

A synergistic effect through multisectional collaboration (e.g. the youth services section, the MOH, the education section) was also required to promote participation by all key stakeholders. For example, multisectional dialogue (e.g. regular progress meetings, the joint meeting regarding children's development and CBR) was functional towards making decisions and taking action for educational issues. In addition, youth club members participate in disability-related activities (D-II), whilst they encourage disabled people to participate in youth events (D-III) with the cooperation of the SSO and the youth services officer. Through mutual participation and reflection, youth members expanded their view of disability and community issues.

It was also important to develop sustainable local activities at the grass-roots level. To ensure their sustainability, one of the key human resources was the coordinator or leader, who could promote all key stakeholders in this study. Capacity-building of disabled leaders and family members would be required.

By comparison with the national CBR programme plan (Ministry of Social Services, 2012), the analysis indicates that 
the division's CBR programme comes across challenges in terms of more inclusive development and a win-win relationship amongst stakeholders (D-II and IV). Because the government has the initiative in conducting CBR activities under the national programme, 'community-oriented projects' are common rather than 'community-initiated projects' (Peat, 1997). This runs the risk of residents' excessive dependence on government services such as financial support, which can lead to the disempowerment of disabled people in some cases. On the other hand, as shown in Table 4, hitherto non-governmental organisations have not implemented programmes on CBR in the study sites. It would be realistic that the government programme should be utilised as one of the local resources in rural areas. Therefore, win-win relationships amongst all key stakeholders and collaborative plans and actions would be important in promoting participation in each dimension, whilst taking account of the risks of dependency and disempowerment. In particular, local government officers would be required to conduct collaborative practice, including planning, acting, and evaluating, with disabled people.

\subsection{Reflecting the process and participation in research}

The twin-track approach (International Disability and Development Consortium, 2012; Kuno \& Seddon, 2003), which the present study adapts as its theoretical framework, underlines the significance of combinations of empowerment (disability-specific approach) and inclusion (community approach) towards CBID. This study shows an example of the approach in rural areas.

During the study period, we promoted participation in four dimensions: D-I, D-II, D-III and D-IV. In line with community needs and scenarios as well as the results of research, the focus has shifted across a wide range of issues from disabled people's participation in local activities (D-I), to mutual cooperation with youth clubs and disabled people (D-II and D-III), inclusive educational development (D-II and D-IV), and raising awareness (D-II).

As Noffke \& Stevenson (1995) state, the process of action research was neither simple nor straightforward. We adapted the steps and focuses along the situation in each case. We believe that this is one of the realities in community-based practice by means of action research.

In relation to the participation of stakeholders in PLA, Pretty et al. (1996) describe stages of participation with varying levels of involvement in the community, ranging from passive participation to self-mobilisation. This research involved disabled people and other local stakeholders gradually throughout the progress of the activities. Because the action plan was not made in advance, we needed to decide the steps and strategies collaboratively, which depended on the situations of the CBR programme and the stakeholders' relationships in local areas. While this is not the ideal way, it is one of the natural processes with outsiders in CBR.

\section{Acknowledgements}

We would like to express our sincere gratitude to the Department of Social Services, including the first author's counterpart, Ms Saroja Priyani, for providing us with this precious research opportunity. The authors are very grateful to Professor Tatsuya Fujii of Sophia University for his useful comments on an earlier draft of this paper. We are also grateful to JICA Sri Lanka office and JICA volunteers for their valuable cooperation in our research.

\section{References}

Boyce, W., \& Lysack, C. (2000). Community participation: uncovering its meanings in CBR. In Thomas M, Thomas MJ (ed.), Selected Readings in Community Based Rehabilitation series Bangalore: Asia Pacific Disability Rehabilitation Journal Group, 1, 42-58.

Department of Census and Statistics. (2012). Population of Sri Lanka by District. Colombo: Department of Census and Statistics.

Finkenflügel, H., Wolffers, I., \& Huijsman, R. (2005). The evidence base for community-based rehabilitation: a literature review. International Journal of Rehabilitation Research, 28, 187-201. http://dx.doi.org/10.1097/00004356-200509000-00001

Freire, P. (1970). Pedagogy of the Oppressed. New York: Herder and Herder.

Gauld, S., Smith, S., \& Kendall, M.B. (2011). Using participatory action research in community-based rehabilitation for people with acquired brain injury: from service provision to partnership with Aboriginal communities. Disability and Rehabilitation, 33, 1901-1911. http://dx.doi.org/10.3109/09638288.2010.550382

Greenwood, D. J., \& Levin, M. (1998). Introduction to Action Research: Social Research for Social Change. Thousand Oaks: Sage.

Higashida, M. (2014a). Local resources of disabled people in Sri Lanka: Action research on community-based rehabilitation programme. Sociology and Anthropology, 2(4) 159-167. 
Higashida, M. (2014b). Community mobilisation in a CBR programme in a rural area of Sri Lanka. Disability, CBR \& Inclusive Development, 25(4) 43-60.

Higashida, M., Illangasingha, M. G., \& Kumara, M. R. S. (2015). Developing local resources in community-based rehabilitation programme in Sri Lanka: Follow-up study in Anuradhapura. International Journal of Social Work and Human Services Practice, 3(1) (in press)

International Disability and Development Consortium. (2012). CBR Guidelines as a Tool for Community Based Inclusive Development.

http://iddcconsortium.net/sites/default/files/resources-tools/files/brochure_summary_bat.pdf

International Labour Organization, United Nations Educational, Scientific and Cultural Organization, \& World Health Organization. (2004). CBR: A strategy for rehabilitation, equalization of opportunities, poverty reduction and social inclusion of people with disabilities: joint position paper 2004. Geneva: WHO.

Kawakita, J. (1967). Hasso-Ho. Tokyo: Chuo-Koronsha. (in Japanese)

Kumar, S. (2002). Methods for Community Participation: A complete guide for practitioners. London: ITDG.

Kuno, K., \& Seddon, D. (2003). Kaihatsu ni okeru Shogaisha Bunya no Twin-Track Approach no Jitsugen ni Mukete (Toward a twin-track approach in the disability sector in development). Tokyo: JICA. (in Japanese)

Lewin, K. (1946). Action research and minority problems. Journal of Social issues, 2, 34-46. http://dx.doi.org/10.1111/j.1540-4560.1946.tb02295.x

Ministry of Social Services. (2012). Draft of CBR Five Year Action Plan. Battaramulla: Ministry of Social Services. http://www.socialwelfare.gov.lk/web/images/stories/pdf/cbr_national_plan_draft2.pdf, accessed 1 Feb 2015

Ministry of Social Services. (2013). Performance Report 2012. Battaramulla: Ministry of Social Services.

Noffke, S. E., \& Stevenson, R. B. (1995). Educational Action Research: Becoming practically critical. Cochran-Smith M. (ed.). New York: Teachers College Press.

Peat, M. (1997). Community Based Rehabilitation. London: Saunders.

Pollard, N., \& Sakellariou, D. (2008). Operationalizing community participation in community-based rehabilitation: Exploring the factors. Disability and Rehabilitation, 30, 62-70. http://dx.doi.org/10.1080/09638280701192980

Pretty, J. N., Guijt, I., Thompson, J., \& Scoones, I. (1996). Participatory Learning and Action: A Trainer's guide. London: IIED.

Rifkin, S. B., \& Kangare, M. (2002). What is participation? In Hartley, S. (ed.), Community-Based Rehabilitation $(C B R)$ as a Participatory Strategy in Africa. London: University College London. 37-49.

Rifkin, S. B., Muller, F., \& Bichmann, W. (1988). Primary health care: on measuring participation. Social Science and Medicine, 26, 931-940. http://dx.doi.org/10.1016/0277-9536(88)90413-3

Sharma, M. (2004). Viable methods for evaluation of community-based rehabilitation programmes. Disability and Rehabilitation, 26, 326-334. http://dx.doi.org/10.1080/09638280410001662923

United Nations. (2000). The United Nations and Disabled Persons: The first 50 years. 2000. http://www.un.org/esa/socdev/enable/dis50y00.htm

United Nations. (2006). United Nations Conventions on the Right of Persons with Disabilities and Optional Protocol. http://www.un.org/disabilities/documents/convention/convoptprot-e.pdf

World Health Organization. (2010). Community-Based Rehabilitation: CBR guidelines. Geneva: WHO.

\section{(c) EY}

This work is licensed under a Creative Commons Attribution 3.0 License. 